\title{
ELABORAÇÃO E CARACTERIZAÇÃO FÍSICO-QUÍMICA E SENSORIAL DE GELEIAS PRODUZIDAS A PARTIR DE DIFERENTES GENÓTIPOS DE MORANGO
}

\author{
F. A. de SOUZA', M. B. NIEDERMEYER ${ }^{2}$ A. G. A. TRINDADE ${ }^{3}$, D. F. dos SANTOS $^{4}$, C. S. M. \\ LIMA $^{5}$, V. Z. PINTO ${ }^{6}$ \\ ${ }^{1}$ Universidade Federal da Fronteira Sul, Mestra em Ciência e Tecnologia de Alimentos \\ ${ }^{2}$ Universidade Federal da Fronteira Sul, Doutora em Ciência de Alimentos \\ ${ }^{3}$ Universidade Federal da Fronteira Sul, graduanda em Agronomia \\ ${ }^{4}$ Universidade Federal da Fronteira Sul, graduando em Engenharia de Alimentos \\ ${ }^{5}$ Universidade Federal da Fronteira Sul, Doutora Agronomia \\ ${ }^{6}$ Universidade Federal da Fronteira Sul, Doutora em Ciência e Tecnologia Agroindustrial \\ E-mail para contato: vania.pinto@uffs.edu.br
}

RESUMO - O morango (Fragaria $\times$ ananassa Duch) é uma fruta explorada em diversos produtos processados, tal como geleias, assim promovendo a acessibilidade ao consumo dessa fruta. Neste trabalho objetivou-se avaliar a interferência de diferentes genótipos de morango no processamento e em características físico-químicas e sensoriais de geleias. Para isto, foram utilizadas as seleções CREA FRF LAM01, CREA FRF LAM18, CREA FRF PA109 e CREA FRF FC104 sob manejo orgânico. As geleias foram caracterizadas pela análise sensorial e determinação de acidez titulável, sólidos solúveis, ratio, $\mathrm{pH}$, teor de compostos fenólicos totais e antocianinas totais. Sensorialmente não foram demonstradas diferenças significativas $(\mathrm{p}<0,05)$ entre as geleias produzidas. Com relação a caracterização físico-química das amostras houve variação $(\mathrm{p}<0,05)$ entre a acidez titulável e teor de sólidos solúveis em algumas amostras, porém o cálculo do ratio mostra apenas a amostra CREA FRF PA 109 destacando-se das demais, com um ratio de 179,40 $\pm 0,44$ e as demais em uma faixa de 147,75 a 159,78. O teor de compostos fenólicos totais e antocianinas totais se mostrou superior $(\mathrm{p}<0,05)$ na amostra CREA FRF LAM18, sendo 49,39 $\pm 3,88$ e 2,38 \pm 0,18 , respectivamente. Com este estudo observa-se a aceitação não se alterando de acordo com o genótipo utilizado na produção de geleia, porém, houve variação nas características físico-químicas, podendo assim ser um indicativo para o produtor selecionar o melhor genótipo para o seu produto.

Palavras-chave: Fragaria $\times$ ananassa Duch, geleia, compostos fenólicos, antocianinas.

ABSTRACT - The strawberry (Fragaria $\times$ ananassa Duch) is a fruit explored in several processed products, such as jams, thus promoting accessibility to the consumption of this fruit. This work aimed to evaluate the interference of different strawberry genotypes in the processing and in the physicochemical and sensory characteristics of jellies. For this, the selections CREA FRF LAM01, CREA FRF LAM18, CREA FRF PA109 and CREA FRF FC104 were used under organic management. The jellies were characterized by sensory analysis and determination 
of titratable acidity, soluble solids, ratio, $\mathrm{pH}$, content of total phenolic compounds and total anthocyanins. Sensorially, there were no significant differences ( $p<0.05)$ between the jellies produced. Regarding the physical-chemical characterization of the samples, there was variation $(\mathrm{p}<0.05)$ between the titratable acidity and soluble solids content in some samples, however the ratio calculation shows only the sample CREA FRF PA 109 standing out from the others, with a ratio of $179.40 \pm$ 0.44 and the others in a range of 147.75 to 159.78 . The content of total phenolic compounds and total anthocyanins was higher $(\mathrm{p}<0.05)$ in the sample CREA FRF LAM18, being $49.39 \pm 3.88$ and $2.38 \pm 0.18$, respectively. With this study, acceptance is observed, not changing according to the genotype used in the production of jelly, however, there was variation in the physical-chemical characteristics, thus being an indication for the producer to select the best genotype for his product.

\section{INTRODUÇÃO}

O morango (Fragaria $\times$ ananassa Duch.) é uma fruta não-climática, com grande aceitação no mercado consumidor pela sua atraente coloração vermelha, aroma e sabor agradáveis. O maior consumo da fruta ocorre de forma in natura, e cada vez mais, os produtos processados e com valor agregado ganham destaque para aumentar a vida útil das frutas (PATRAS et al., 2011). Essas frutas in natura possuem vida útil curta, presença de vários compostos bioativos promotores da saúde, como antocianinas, polifenóis e vitamina $\mathrm{C}$, que refletem a importância do morango e de seus produtos como benéficos à saúde (PATRAS et al., 2011).

Um crescente interesse tem sido dedicado ao conteúdo destes fitoquímicos dos pequenos frutos, tais como framboesa, mirtilo e morango (REKIKA et al., 2005) e atenção especial tem sido dada à capacidade antioxidante desses frutos. Alguns estudos mostraram que a atividade antioxidante de extratos vegetais, como uvas, mirtilos e morangos foi correlacionada com o conteúdo de compostos fenólicos totais. Em morangos, o ácido elágico juntamente com alguns flavanóides (antocianinas, proantocianinas, catequina e epicatequina) são os principais compostos com propriedades antioxidantes. Sabe-se que esses compostos influenciam a qualidade, a aceitabilidade e a estabilidade dos alimentos, agindo como ingredientes, corantes ou antioxidantes (REKIKA et al., 2005).

Além disso, a avaliação de novas seleções e cultivares de morango em relação ao conteúdo de fitoquímicos, bem como a conservação destes compostos através do processamento de geleias deve ser considerado em programas de melhoramento, juntamente com o desempenho de campo e as respostas das seleções às práticas culturais (REKIKA et al., 2005). Visto que a escolha dos genótipos de morangueiro vem a ser um dos fatores que determinam parte do sucesso do cultivo do morangueiro, bem como, influenciam na obtenção de características físico-químicas desejáveis dos morangos (DUARTE FILHO et al., 2007). Diante disto, programas de melhoramento buscam a melhoria de materiais a fim de selecionar características desejáveis, onde, assim os genótipos de morangueiro CREA FRF LAM01, CREA FRF LAM18, CREA FRF PA109 e CREA FRF FC104 encontram-se em fase de melhoramento e testes, e se as informações sobre estes ainda se encontram defasadas.

Muitos dos produtos processados de morango, tais como suco, néctar, purê e suco concentrado, bem como geleias são amplamente consumidos. A geleia é um alimento de umidade intermediária e as etapas de processamento industrial mais comuns são a concentração 
de suco de frutas, o armazenamento destes em tanques, a rediluição e o preparação das geleias por aquecimento sob vácuo, engarrafamento, fechamento sob vácuo e resfriamento (PATRAS et al., 2011). A temperatura durante o processamento é geralmente $90{ }^{\circ} \mathrm{C}$, e a geleia é mantida nessa temperatura por alguns minutos para atingir o aquecimento e a textura adequados (WICKLUND et al., 2005).

A aceitação ou rejeição de geleias pelos consumidores depende da garantia de retenção de cor, sabor, relação doçura e acidez, qualidade do aroma e conteúdo de nutrientes presentes nos frutos frescos. Além disso, durante o armazenamento observa-se que geleias de morango escurecem facilmente devido ao elevado teor de antocianinas, sensível à luz e temperatura (MIGUEL; ALBERTINI; SPOTO, 2009). Assim, busca-se garantir que estes produtos mantenham as características próximas aos frutos in natura ampliando sua aceitação e a vida útil do produto.

Na produção de geleias muitos fatores são importantes, Rekika et al. (2005) aponta a presença de antocianinas como a principal razão da coloração de geleias atrativa de geleias. E Magalhães (2012) mostra que geleias com uma elevada acidez total têm a estrutura do gel mais flexível. Assim, conhecer as propriedades físico-químicas da fruta no preparo de uma geleia, pode ser algo de extrema importância para o produtor sendo a matéria prima um motivo para aplicar correções e garantir um produto dentro dos padrões desejados. E com o desenvolvimento de seleções de genótipos de morangueiro novos, passa a ser importante avaliar como as características intrínsecas de cada genótipo interferem no processamento destas frutas e a aceitabilidade de seus produtos, assim objetivou-se elaborar geleias utilizando diferentes seleções de morango e avaliar as características sensoriais e físico-químicas dos produtos.

\section{MATERIAL E MÉTODOS}

\subsection{Materiais}

Como material vegetal foram utilizadas frutas de quatro seleções de morangueiro oriundas de plantas de segundo ano de produção, cedidas no ano de 2017 pela Universidade do Estado de Santa Catarina (UDESC) - Centro de Ciências Agroveterinárias (CAV), para realização de experimentos na UFFS nas condições edafoclimáticas de Laranjeiras do Sul/PR, sob manejo de cultura orgânico.

As seleções italianas utilizadas foram: CREA FRF LAM01, CREA FRF LAM18, CREA FRF PA109 e CREA FRF FC104. Os genótipos oriundos da Itália foram provenientes do programa de melhoramento do Consiglio per la Ricerca in Agricoltura e l'Analisi dell'Economia Agraria - Unitá di Ricerca per la Frutticoltura di Forlì (CREA-FRF). Estes materiais foram enviados para o Brasil através de uma parceria com o CAV-UDESC.

O açúcar cristal foi adquirido no mercado local e a pectina foi cedia gentilmente pela empresa CPKelco. Os demais reagentes utilizados foram de grau analítico.

\subsection{Métodos}

\subsubsection{Caracterização físico-química}

Para a elaboração das geleias em uma panela de aço inoxidável, sob agitação manual constante, foram adicionados os morangos previamente triturados e o açúcar cristal (50:50\%, 
$\mathrm{m} / \mathrm{m}$ ), sendo submetidos à cocção até atingir a concentração de aproximadamente, $63^{\circ}$ Brix. Ao atingir a concentração foi adicionada $0,5 \%$ de pectina e mantido sob agitação constante até que todos os ingredientes fossem solubilizados e então o aquecimento foi interrompido. As geleias foram armazenadas em recipientes de vidro hermeticamente fechados sob refrigeração $(6 \pm 4$ $\left.{ }^{\circ} \mathrm{C}\right)$ até sua utilização.

A acidez titulável foi quantificada segundo a metodologia descrita por Zenebon; Pascuet, (2008). $5 \mathrm{~g}$ das amostras de geleia foram pesadas e diluídas em $50 \mathrm{~mL}$ de água destilada, juntamente com 2 gotas de indicador fenolftaleína, e posteriormente tituladas até a alteração de cor. $\mathrm{O}$ pH foi determinando anteriormente a titulação da acidez titulável através da leitura do $\mathrm{pH}$ com potenciômetro de bancada.

O teor de sólidos solúveis foi analisado diretamente em refratômetro de bancada a $20^{\circ} \mathrm{C}$ e expressos em ${ }^{\circ}$ Brix (ZENEBON; PASCUET, 2008). O ratio foi determinado através da razão entre o teor de sólidos solúveis e a acidez total.

Para a quantificação do teor de compostos fenólicos totais e antocianinas um extrato metanólico de cada amostra foi utilizado, esse extrato foi preparado com $500 \mathrm{mg}$ de amostra em $5 \mathrm{~mL}$ de metanol acidificado ( $\mathrm{pH} \mathrm{1,0).} \mathrm{As} \mathrm{amostras} \mathrm{foram} \mathrm{dispostas} \mathrm{em} \mathrm{banho} \mathrm{ultrassom} \mathrm{a}$ temperatura ambiente por $30 \mathrm{~min}$, seguidas de centrifugação (5095 rcf por $15 \mathrm{~min}$ ). Na sequência o sobrenadante foi coletado em microtubos de $1,5 \mathrm{~mL}$ armazenados em freezer a $80^{\circ} \mathrm{C}$ até a análise (FREDES et al., 2014).

O teor de compostos fenólicos totais foi determinado conforme método descrito por Singleton; Rossi Jr., (1965). Primeiramente pipetou-se, em microplacas, $10 \mu \mathrm{L}$ de extrato metanólico, $204 \mu \mathrm{L}$ de água destilada, $44 \mu \mathrm{L}$ de Folin-Ciocalteau $0,25 \mathrm{~N}$ e após 5 min de incubação adicionou-se $22 \mu \mathrm{L}$ de carbonato de sódio $10 \%$, realizada breve agitação e repouso de $2 \mathrm{~h}$ no escuro. Posteriormente foram realizadas leituras da absorbância no comprimento de onda de $765 \mathrm{~nm}$ em espectrofotômetro. Uma curva padrão com ácido gálico (AG), nas concentrações $0 ; 0,043 ; 0,087 ; 0,130 ; 0,173 \mathrm{mM}$, foi utilizada para determinar a concentração dos fenóis totais. Os resultados foram expressos em AGE $\mathrm{g}^{-1}$ de amostra.

A concentração de antocianinas foi determinada conforme descrito por Lee; Francis, (1972), pela leitura da absorbância do extrato metanólico preparado, no comprimento de onda de $520 \mathrm{~nm}$ em espectrofotômetro e o conteúdo estimado de acordo com a equação 1 . Os resultados foram expressos em $\mathrm{mg} 100 \mathrm{~g}^{-1}$ amostra.

$$
\text { Antocianinas Totais }(\mathrm{mg} / 100 \mathrm{~g} \text { amostra })=(\text { Abs x V) } /(\mathrm{m} \mathrm{x} \mathrm{98,2)}) 100
$$

\subsubsection{Análise Sensorial}

A análise sensorial das geleias foi realizada através de teste afetivo de aceitação com 70 provadores não treinados e maiores de 18 anos. Os testes foram realizados em cabines individuais e os julgadores receberam 4 amostras, de $10 \mathrm{~g}$, à temperatura de $22{ }^{\circ} \mathrm{C}$ (DUTCOSKY, 2013), em copos descartáveis, codificados com números aleatórios de 3 dígitos. Água foi servida para o consumo entre as amostras e foi solicitado aos julgadores que após provarem as amostras, da esquerda para direita, avaliassem os atributos: cor, sabor, aroma, textura e impressão global, utilizando escala hedônica de 9 pontos, com variação de gostei muitíssimo (9) a desgostei muitíssimo (1). Além disso, foi avaliada a intenção de compra utilizando escala de 5 pontos variando entre certamente compraria (5) a certamente não compraria (1), bem como um espaço para comentários e sugestões. 


\subsubsection{Análise Estatística}

As análises de caracterização físico-química das formulações de geleias foram realizadas em triplicata e os resultados foram expressos com o valor médio \pm desvio padrão da média. Sendo que, as médias obtidas foram avaliadas através de análise de variância (ANOVA) e teste de Tukey com nível de significância de $5 \%$, utilizando software adequado.

\section{RESULTADOS E DISCUSSÃO}

\subsection{Caracterização físico-química}

Na Tabela 1 estão apresentados os resultados para as análises de acidez titulável, teor de sólidos solúveis, o ratio e o $\mathrm{pH}$ das geleias elaboradas utilizando diferentes seleções de morango cultivados de forma orgânica.

Tabela 1 - Acidez total, teor de sólidos solúveis, ratio e $\mathrm{pH}$ das geleias de morangos de diferentes seleções.

\begin{tabular}{ccccc}
\hline Seleções & $\begin{array}{c}\text { Acidez titulável } \\
(\mathrm{g} \text { de ácido cítrico } \\
\left.100 \mathrm{~g}^{-1}\right)\end{array}$ & $\begin{array}{c}\text { Teor de sólidos } \\
\text { solúveis }\left({ }^{\circ} \text { Brix }\right)\end{array}$ & Ratio & $\mathrm{pH}$ \\
\hline FRF Lam 18 & $0,43 \pm 0,01^{\mathrm{a}}$ & $62,83 \pm 0,38^{\mathrm{a}}$ & $147,75 \pm 3,46^{\mathrm{b}}$ & $3,74 \pm 0,07^{\mathrm{ab}}$ \\
FRF Lam 01 $^{\mathrm{b}}$ & $0,39 \pm 0,01^{\mathrm{b}}$ & $61,67 \pm 0,29^{\mathrm{b}}$ & $156,72 \pm 1,60^{\mathrm{b}}$ & $3,71 \pm 0,01^{\mathrm{ab}}$ \\
FRF Pa 109 & $0,35 \pm 0,00^{\mathrm{b}}$ & $62,83 \pm 0,14^{\mathrm{a}}$ & $179,40 \pm 0,44^{\mathrm{a}}$ & $3,66 \pm 0,03^{\mathrm{b}}$ \\
FRF FC 104 & $0,37 \pm 0,03^{\mathrm{b}}$ & $58,90 \pm 0,17^{\mathrm{c}}$ & $159,78 \pm 4,65^{\mathrm{b}}$ & $3,77 \pm 0,01^{\mathrm{a}}$ \\
\hline
\end{tabular}

* Médias \pm desvio padrão de três determinações. Médias seguidas pela mesma letra nas colunas não diferem estatisticamente entre si pelo teste de Tukey ao nível de $95 \%$ de confiança $(\mathrm{p}<0,05)$.

A acidez titulável das geleias divergiu $(\mathrm{p}<0,05)$ somente para a seleção FRF Lam 18 com $0,43 \pm 0,01 \mathrm{~g}$ de ácido cítrico $100 \mathrm{~g}^{-1}$, sendo superior as demais com valores entre $0,35 \mathrm{e}$ $0,39 \mathrm{~g}$ de ácido cítrico $100 \mathrm{~g}^{-1}$. Musa (2018), avaliou diretamente diferentes cultivares de morango em diferentes condições de manejo, obtendo para acidez titulável valores entre 0,58 a $0,91 \mathrm{~g}$ ácido cítrico $100 \mathrm{~g}^{-1}$, demonstrando assim que a acidez pode variar muito de acordo com o cultivar e condição de manejo aplicada. Conforme Magalhães (2012) a acidez alta $(0,5$ a 0,8$)$ pode até mesmo destruir ou afetar a estrutura pela hidrólise da pectina, assim ao se trabalhar com um genótipo extremamente ácido o processamento da fruta para se tornar geleia mostra-se prejudicado, neste caso as geleias produzidas apresentam acidez baixa, então não afetando a estrutura do gel formado..

O teor de sólidos solúveis foi maior $(\mathrm{p}<0,05)$ para as amostras FRF Lam 18 e FRF Pa 109 , com 62,83 $\pm 0,38$ e 62,83 $\pm 0,14{ }^{\circ}$ Brix, respectivamente, seguidos pelas amostras FRF Lam 01 e FRF FC 104. A legislação brasileira impõe o limite de mínimo de $65 \%$ de sólidos solúveis totais para geleias (TORREZAN, 1998), deste modo todas as geleias produzidas apresentaram teores menores que o estabelecido pela legislação. Para que os produtos se enquadrem dentro do estabelecido seria necessário aumentar o tempo de cocção para concentrar os sólidos, assim com a utilização de morangos com maior teor de sólidos solúveis o tempo de cocção pode ser reduzido. 
Quanto ao ratio, este divergiu ( $\mathrm{p}<0,05)$ somente para a geleia FRF Pa 109, devido ao seu baixo valor de acidez em relação as demais e maior $(\mathrm{p}<0,05)$ teor de sólidos solúveis em relação as demais, assim a relação sólidos solúveis acidez total titulável é incrementada. Este valor refere-se a como se dá o equilíbrio entre o sabor ácido e a doçura de frutos, tornando-os mais agradáveis. No entanto, para geleias, o elevado ratio é reflexo do elevado teor de sólidos solúveis, indicando que o produto apresenta elevada doçura. Para um bom paladar a combinação agradável de açúcar e acidez deve ser equilibrado.

$\mathrm{O} \mathrm{pH}$ das amostras de geleias analisadas divergiu significativamente para algumas amostras, com o menor $(\mathrm{p}<0,05)$ resultado para a amostra FRF Pa 109 e maior $(\mathrm{p}<0,05)$ para a amostra FRF FC 104 com 3,66 $\pm 0,03$ e 3,77 $\pm 0,01$, respectivamente. Igualmente a acidez titulável o pH pode variar de acordo com o genótipo e manejo. Sendo estes resultados encontrados elevados para geleias, que idealmente devem ter um $\mathrm{pH}$ próximo de 3,0 que implica na formação correta do gel (TORREZAN, 1998). Assim, as diferentes seleções de morangos necessitam de correção de pH para a produção de geleias, favorecendo a formação do gel pela pectina e reduzindo o ratio, fazendo com que haja um melhor equilíbrio entre o teor de sólidos solúveis, que reflete a doçura e a acidez do produto.

Tabela 2 - Teor de compostos fenólicos e antocianinas das geleias de morango de diferentes seleções.

\begin{tabular}{ccc}
\hline Seleções & $\begin{array}{c}\text { Compostos fenólicos totais } \\
\left(\mathrm{AGE} \mathrm{g}^{-1}\right)\end{array}$ & Antocianinas $\left(\mathrm{mg} \mathrm{100} \mathrm{\textrm {g } ^ { - 1 } )}\right.$ \\
\hline FRF Lam 18 & $49,39 \pm 3,88^{\mathrm{a}}$ & $2,38 \pm 0,18^{\mathrm{a}}$ \\
FRF Lam 01 & $29,86 \pm 4,98^{\mathrm{b}}$ & $1,15 \pm 0,11^{\mathrm{c}}$ \\
FRF Pa 109 & $34,15 \pm 0,58^{\mathrm{b}}$ & $1,47 \pm 0,14^{\mathrm{c}}$ \\
FRF FC 104 & $29,42 \pm 4,39^{\mathrm{b}}$ & $1,99 \pm 0,07^{\mathrm{b}}$ \\
\hline
\end{tabular}

* Médias \pm desvio padrão de três determinações. Médias seguidas pela mesma letra nas colunas não diferem estatisticamente entre si pelo teste de Tukey ao nível de $95 \%$ de confiança $(\mathrm{p}<0,05)$.

Os valores do teor de antocianinas totais dispostos na Tabela 2 mostraram-se equilibrados visto que Pinto (2008) avaliou diretamente 7 diferentes cultivares de morango, estes apresentaram teores de antocianinas totais entre 6,9 e $32 \mathrm{mg} 100 \mathrm{~g} \mathrm{~g}^{-1}$, dentre as amostras de geleia produzidas e analisadas a com maior $(\mathrm{p}>0,05)$ teor de antocianinas totais foi a geleia do genótipo FRF Lam 18 com 2,38 $\pm 0,18 \mathrm{mg} 100 \mathrm{~g}^{-1}$ seguida das amostras FRF FC 104, FRF

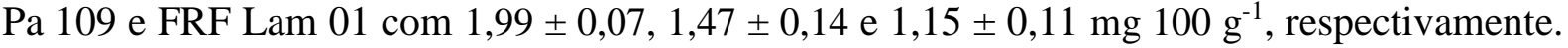
Considerando o processamento desta geleia, pode-se considerar esse baixo teor devido a possíveis deteriorações durante o período de cocção. Porém, uma elevada concentração de antocianinas em geleias favorece a formação da cor vermelha característica do produto, sendo também responsáveis pela perda de qualidade durante o armazenamento, devido a sua degradação e formação de cor escura (REKIKA et al., 2005). Então faz-se necessário trabalhar com um equilíbrio desses dois fatores.

Com relação ao teor de compostos fenólicos totais, Pinto (2008) encontrou valores elevados em suas amostras de morango, com valores entre 205 a $318 \mathrm{mg} 100 \mathrm{~g}^{-1}$, nas amostras analisadas o maior teor de compostos fenólicos totais foi da amostra FRF Lam 18 com 49,39 \pm 3,88 AGE g $^{-1}$, seguida das demais amostras com valores entre 29,42 e 34,15 AGE g $^{-1}$.

\subsection{Análise Sensorial}


Quanto a análise sensorial, esta foi realizada com 70 provadores não treinados, sendo que destes, $40 \%$ eram do sexo masculino e $60 \%$ feminino. Adicionalmente, $80 \%$ dos provadores possuíam idade entre 18 e 25 anos, $12 \%$ de 26 a 33 e $8 \%$ acima de 33 anos. Quando perguntados quanto a frequência com que consomem geleias de frutas $47 \%$ declararam que consomem geleia "Às vezes" (todo mês), 15 \% "frequentemente" (toda semana), 28,5 \% "Muito pouco" (a cada 6 meses) e 9,5\% “Apenas em ocasiões especiais".

Os resultados obtidos quanto aos atributos sensoriais e de intenção de compra são apresentados na Tabela 3.

Tabela 3 - Características sensoriais das geleias de morango de diferentes seleções.

\begin{tabular}{cccccc}
\hline Seleções & Cor* & Aroma* & Sabor* & Textura* & $\begin{array}{c}\text { Intenção de } \\
\text { compra* }\end{array}$ \\
\hline FRF Lam 18 & $7,9^{\mathrm{a}}$ & $7,7^{\mathrm{a}}$ & $7,3^{\mathrm{a}}$ & $7,6^{\mathrm{a}}$ & $3,8^{\mathrm{a}}$ \\
FRF Lam 01 & $8,1^{\mathrm{a}}$ & $7,5^{\mathrm{a}}$ & $7,1^{\mathrm{a}}$ & $7,6^{\mathrm{a}}$ & $3,7^{\mathrm{a}}$ \\
FRF Pa 109 & $7,7^{\mathrm{a}}$ & $7,7^{\mathrm{a}}$ & $7,5^{\mathrm{a}}$ & $7,6^{\mathrm{a}}$ & $4,0^{\mathrm{a}}$ \\
FRF FC 104 & $7,9^{\mathrm{a}}$ & $7,5^{\mathrm{a}}$ & $7,0^{\mathrm{a}}$ & $7,3^{\mathrm{a}}$ & $3,8^{\mathrm{a}}$ \\
\hline
\end{tabular}

* Médias de 70 avaliadores. Médias seguidas pela mesma letra nas colunas não diferem estatisticamente entre si pelo teste de Tukey ao nível de $95 \%$ de confiança $(\mathrm{p}<0,05)$.

As geleias elaboradas com as diferentes seleções de morangos não apresentaram diferenças significativas $(\mathrm{p}<0,05)$, demonstrando que os provadores não perceberam diferenças sensoriais entre os genótipos utilizados no preparo. No entanto, alguns comentários foram verificados nas fichas de avaliação, sendo que o principal apontamento foi de que algumas formulações apresentaram sabor doce ressaltado. Esta sensação pode ser consequência do ratio elevado na amostra FRF Pa 109, devido as propriedades desse genótipo transferidas para a geleia.

Quanto aos atributos avaliados, as médias para cor, sabor, textura e aroma variaram de 7 a 8,1, que de acordo com a escala aplicada, correspondem a gostei regularmente e gostei muito. Quanto a intenção de compra do produto, as médias foram de 3,8 que conforme escala hedônica de 5 pontos utilizada, corresponde a possivelmente compraria. Os resultados mostram que além das geleias terem obtido boa aceitação sensorial, independente do genótipo utilizado, também haveria por parte dos provadores a intenção de comprar o produto produzido a partir de todos os genótipos.

\section{CONCLUSÃO}

Dentre as geleias produzidas e suas propriedades físico-químicas, a amostra do genótipo FRF Lam 18 ressaltou-se perante as demais, pelo maior $(\mathrm{p}<0,05)$ teor de compostos bioativos, compostos fenólicos e antocianinas, e maior $(\mathrm{p}<0,05)$ acidez titulável e teor de sólidos solúveis. Nos demais genótipos não houve variação representativa, em características físicoquímicas. Esta informação somada a variação das características físico-químicas não influenciaram os resultados da análise sensorial das amostras, visto que as notas para os atributos cor, aroma, sabor e textura variaram de "gostei regularmente" a "gostei muito" e a intensão de compra indica que os provadores possivelmente comprariam as quatro amostras de geleias testadas. É possível concluir que as características físico-químicas destes genótipos não 
interferiram significativamente no processamento dessas geleias e que para a produção de geleias, dentre as seleções testadas pode-se optar pela mais viável e acessível ao produtor, sem perdas na aceitação do consumidor.

\section{AGRADECIMENTOS}

Convênio UDESC e edital de apoio à agroecologia (681/UFFS/2017).

\section{REFERÊNCIAS}

DUARTE FILHO, J; ANTUNES, L.E.C; PÁDUA, J.G. Cultivares. In: Morango: conquistando novas fronteiras. DIAS, M.S.C. (coord.). Informe Agropecuário, Belo Horizonte, vol. 28, n. 236, p. 20-23, 2007.

DUTCOSKY, S. D. Análise sensorial de alimentos. 4. ed. Curitiba: Champagnat, 2013. FREDES, C. et al. Comparison of the Total Phenolic Content, Total Anthocyanin Content and Antioxidant Activity of Polyphenol-Rich Fruits Grown in Chile. Ciencia e investigación agraria, v. 41, n. 1, p. 9-10, 2014.

LEE, D. H.; FRANCIS, F. Standardization of Pigment Analyses in Cranberries. HortScience, p. 83-84, 1972.

MAGALHÃES, Vania Silva Carvalho. Caracterização físico-química e aplicabilidade tecnológica da sapota (quararibea cordata Vischer). Dissertação (Programa de PósGraduação em Ciência de Alimentos) - Escola de Agronomia e Engenharia de Alimentos, Universidade Federal de Goiás, Goiânia.

MIGUEL, A. C. A.; ALBERTINI, S.; SPOTO, M. H. F. Cinética da degradação de geleiada de morango. Ciência e Tecnologia de Alimentos, v. 29, n. 1, p. 142-147, 2009.

MUSA, C. I. Caracterização físico-química de morangos de diferente cultivares em sistemas de cultivo distintos no município de Bom Princípio/RS. 2016. Tese (Doutorado em Ambiente e Desenvolvimento) - Programa de Pós-Graduação em Ambiente e Desenvolvimento, Universidade do Vale do Taquari, Lajeado, 2016.

PATRAS, A. et al. Stability and Degradation Kinetics of Bioactive Compounds and Colour in Strawberry Jam during Storage. Food and Bioprocess Technology, v. 4, n. 7, p. 1245-1252, 2011.

PINTO, M. S. Compostos bioativos de cultivares brasileiras de morango (Fragaria $x$ ananassa Duch.): carcaterização e estudo da biodisponibilidade dos derivados de ácido elágico. 2008. Tese (Doutorado em Ciência de Alimentos) - Programa de Pós-graduação em Ciência dos Alimentos Faculdade de Ciências Farmacêuticas, Universidade de São Paulo, São Paulo, 2008.

REKIKA, D. et al. Antioxidant capacity and phenolic content of selected strawberry genotypes. Hort Science, v. 40, n. 6, p. 1777-1781, 2005. 
SINGLETON, V. L.; ROSSI JR., J. A. Colorimetry of Total Phenolics with Phosphomolybdic-Phosphotungstic Acid Reagents. American Journal of Enology and Viticulture, v. 16, n. 3, p. 144-158, 1965.

TORREZAN, R. Manual para a produção de geléias de frutas em escala industrial. EMBRAPA-CTAA. Documentos, 1998.

WICKLUND, T. et al. Antioxidant capacity and colour of strawberry jam as influenced by cultivar and storage conditions. LWT - Food Science and Technology, v. 38, n. 4, p. 387$391,2005$.

ZENEBON, O.; PASCUET, N. S. Métodos físico-químicos para análise de alimentos: normas analíticas do Instituto Adolfo Lutz. 4. ed. São Paulo: Instituto Adolfo Lutz, 2008. 